\title{
A MEDIUM FREQUENCY TRANSFORMER DESIGN FOR SPOT WELDING MACHINE USING SIZING EQUATION AND FINITE ELEMENT ANALYSIS
}

\author{
Serdal Arslan ${ }^{1}$ - İlhan Tarimer ${ }^{2}$ - M.E. Güven ${ }^{3}$ - Sibel Akkaya Oy ${ }^{4}$ \\ ${ }^{1}$ Department of Electrical Engineering, Faculty of Engineering, Harran University, Turkey \\ ${ }^{2}$ Department of Information Systems Engineering, Faculty of Technology, Muğla Sitkı Koçman University, Turkey \\ ${ }^{3}$ Department of Electrical Engineering, Faculty of Technology, Gazi University, Turkey \\ ${ }^{4}$ Marine science and technology engineering, Faculty of Marine Sciences, Ordu University, Turkey
}

\begin{tabular}{l}
\hline ARTICLE INFO \\
\hline Article history: \\
Received: 11.6 .2018$. \\
Received in revised form: 3.10 .2018$. \\
Accepted: 3.10 .2018$. \\
\hline Keywords: \\
Spot welding \\
Transformer \\
Medium frequency \\
Electromagnetic design \\
Size \\
\hline DOI: http://doi.org/10.30765/er.40.3.05
\end{tabular}

\section{Introduction}

Nowadays, spot welding is being used for combining metallic parts almost in every part of the industry. Due to its reliability, the spot welding is widely used in metal industry which needs serial production. Using spot welding machines gains importance by aiming to reduce production costs and to make quick and thorough weldings in industrial practices [1]. Gradually, medium frequency spot welding machines have become better than traditional welding technology. Due to this, designs of welding transformer have also become important. Nowadays, the use of inverter technology in medium frequency

\begin{abstract}
:
In this study, a medium frequency power transformer has been designed analytically and its sizes have been obtained. The transformer's analyses were made numerically by $2 D$ AnsysMaxwell Solver software package. The Solver has also helped to study suitable transformer core and winding samples. Unlike medium frequency transformer, which is generally driven by unipolar $P W M$ method, the designed transformer is driven by bipolar PWM method in the study. The core losses were obtained for different core materials (Trafoperm N3 and Amorfous 2605SA1) by AnsysMaxwell numerical and analytical calculations. The calculated losses for no-load working conditions were compared with each other. The designed transformer has been analyzed for its noload and loaded working conditions magnetically. Finally, the radial and axial forces created in the windings have also been examined for loaded working condition.
\end{abstract}

spot welding machines have begun to be seen frequently. Though the frequency is constant in the conventional spot-welding machines, the new generation spot welding machines' frequency is medium and high. In terms of electricity and welding [2-4], there are several advantages in use of medium and high frequency spot welding machines. For example, they take more energy in same welding size and perform more efficiency. They last the electrode life because of low currents, present high-quality welding facility because of short welding time and reliable welding control $[3,5]$.

In terms of construction, voltage level, and rated power, transformer design is based on the range of

\footnotetext{
* Corresponding author. Tel.:+905058302036

E-mail address: sibelakkaya@odu.edu.tr
} 
application first of all. Thus, considering the fact that while keeping production costs low, power engineers also have to make sure that imposed specifications are compatible. It can be clearly seen that transformer design is a complex task. In addition, depending on the transformer type and its operating frequency, the design methodology may vary significantly [6-7].

Zidaric and et al. [8] have determined hysteresis losses of medium frequency transformer under noload working condition analytically and they have also measured hysteresis loop of inverter. Štumberger and et al. [9] have studied harmonic spectrums and acoustic noise of the current and magnetic flux. Klopčič and et al. [10] have showed that asymmetric part of characteristics causes peaks at primary current and they have also applied several control technics for reducing such peak currents. According to the literature reviews [11-13], core model, core, and copper loss equations were not found for medium frequency spot welding machine due to commercial reasons. Computer aided FEM analysis is one of the indispensable methods for designing medium frequency electric machines [14]. Sakhno and et al. [15], have implemented a 2D eddy current solution to estimate the leakage impedance for a medium frequency welding machine transformer. In [16], a modification of the improved advanced hysteresis control for the resistance spot welding system was developed. In [17], the performances of hysteresis and proportional integral controls were shown to control saturation level in the magnetic core of a welding transformer in a middlefrequency direct current resistance spot welding system (MFDC RSWS). In [18], the methods of PI control and particle swarm optimization PI control were compared in terms of current peaks and harmonics. In [19], the control of a MFDC RSWS was improved by a combined closed-loop control of the welding current and closed-loop control of the iron core saturation level. In [20], a new methodology for determining parameters of a dynamic RSW transformer model was presented.

Unbalanced distribution in total fluxes can lead to high leakage fluxes that increase transformer impedance. However, the impedance of the transformer should be low. Therefore, in order to reduce the impedance, it is necessary to provide the interleaving of primary and secondary windings [21]. Petrun has reported that the core material (Trafoperm N2) which is used in medium frequency spot welding causes losses in $0.1 \mathrm{~mm}$ and $0.27 \mathrm{~mm}$ lamination thickness and different temperature values [22, 23]. $\mathrm{He}$ has stated that the increase of operating temperature may negatively affect the transformer core losses and Trafoperm N2 material is a suitable core for $0.1 \mathrm{~mm}$ spot welding transformer.

In the present study, we have designed a medium frequency power transformer and have analyzed the transformer by finite elements method. We have also made numerical analysis of the transformer by finite elements method considering the three-dimensional structure model. The analyses have approved that the designed transformer is suitable in MFDC RSWS. We have obtained electromagnetic parameters as preliminary design. These parametric values are essential for application of the designed model. The core losses of the designed transformer were calculated by numerical analysis method for two core materials (Trafoperm N3 and Amorfous 26SA1). Dynamic analysis for spot welding system was made as considering core material "Trafoperm N3". The designed transformer for the welding machine was driven by a bipolar PWM.

\section{Designing a medium frequency transformer for welding machines}

Medium frequency spot welding machines are machines that are supplied by 3-phase power due to their power requirements. The spot-welding machine consists of rectifier, inverter, and a medium frequency transformer [24]. The 3-phases plugged on to the machine are converted to DC voltages by a rectifier. In order to obtain the voltages within the range of $1-2 \mathrm{kHz}$ (medium frequency), it is necessary to use an inverter for obtaining a medium frequency. The DC bar voltage is converted to medium frequency $\mathrm{AC}$ voltage by an inverter. The transformer with middle terminal which is designed to work at $1 \mathrm{kHz}$ frequency converts inverter output power to welding current and voltage carrying same frequency. The equivalent circuit diagram of MFDC RSWS is shown in Figure 1.

A narrow stitch image of welding and obtained deep penetration stitches without splashes [25] in a thesis' experimental works have been seen. In these experiments, the welding voltage has been kept low. Despite the higher welding voltage, the welding stitch is widening and it was noticed that the penetration was decreased [25]. For this reason, transformers which are used in medium frequency spot welding machines are reducing type transformers. The voltages of 5-15 volts at transformer outputs are converted to the DC voltages by a full wave rectifier circuit. 


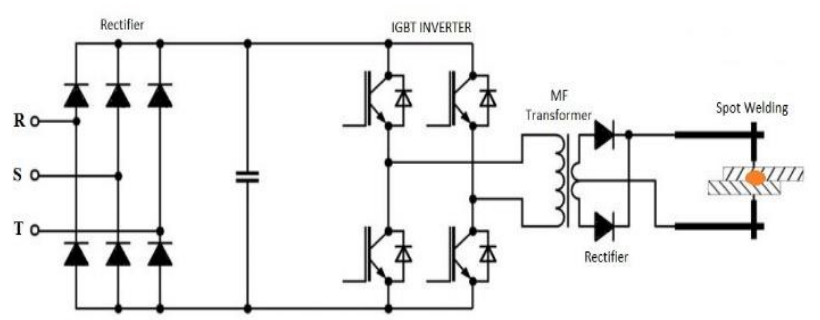

(a)

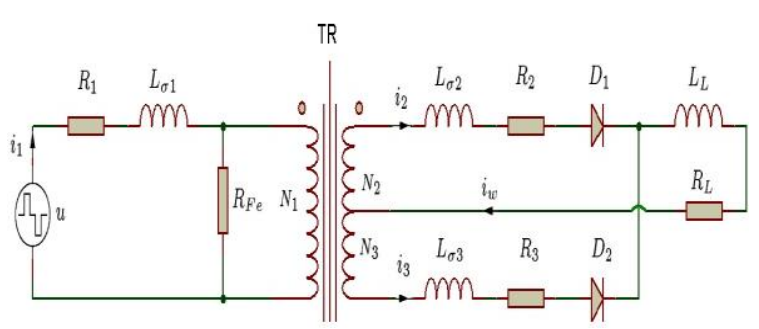

(b)

Figure 1. Power conversion in control and transformer of medium frequency inverter (a), The circuit diagram of medium frequency transformer and load (b)

The asymmetrical design of the transformer in combination with slightly different characteristics of diodes in output rectifier can produce the inconvenient current spikes[10]. The only discrete diodes available suitable for high frequency and medium frequency spot welding are press-pack diodes which require liquid cooling and are complicated to integrate into a transformer. The recovery charge of the diodes also increases the rectifier losses [26].

Since the transformer operates at $1 \mathrm{kHz}$, it is recommended to use high current capability combined with excellent reverse recovery characteristics high-speed diodes to rectify the output current.

As seen from Figure 1a, a DC link capacitor stores large amount of the energy. This increases the risk of IGBTs not to conduct current continuously in case of a fault. It can end up in personal injury, damage to the converter circuit, and drive down the time. As a result of these, equipment certification problems are seen as well. Using high speed fuses may prevent these problems, and protect the entire case. The fuses create inductance and voltage peaks in the circuit. Thus, they lead to the losses. There should be a careful selection of the driver circuits to make the IGBTs' commutations well [27]. The equations for Figure 1 are given below:

$$
\begin{gathered}
0=U_{1}-R_{1} i_{1}+L_{\sigma 1} \frac{d i_{1}}{d t}+N_{1} \frac{d \phi}{d t} \\
0=R_{2} i_{2}+L_{\sigma 2} \frac{d i_{2}}{d t}+N_{2} \frac{d \phi}{d t}+U_{D 1} \\
+R_{L}\left(i_{2}+i_{3}\right)+L_{L} \frac{d\left(i_{2}+i_{3}\right)}{d t} \\
0=R_{3} i_{3}+L_{\sigma 3} \frac{d i_{3}}{d t}-N_{3} \frac{d \phi}{d t}+U_{D 2} \\
+R_{L}\left(i_{2}+i_{3}\right)+L_{L} \frac{d\left(i_{2}+i_{3}\right)}{d t} \\
0=H(B) l_{w}+\frac{B}{\mu_{0}} 2 \delta+\frac{N_{1}^{2}}{R_{F e}} \frac{d \phi}{d t} \\
-N_{1} i_{1}-N_{2} i_{2}+N_{3} i_{3} \\
\tau=\frac{L_{L}}{R_{L}}
\end{gathered}
$$

where; $\mathrm{R}_{1}, \mathrm{R}_{2}, \mathrm{R}_{3}$ are primary and secondary resistances, $\mathrm{R}_{\mathrm{L}}, \mathrm{L}_{\mathrm{L}}$ are load resistance and inductance, $\mathrm{R}_{\mathrm{Fe}}$ is the effects of the eddy current losses accounted for by the resistor, $\mathrm{L} \sigma 1, \mathrm{~L} \sigma 2, \mathrm{~L}_{\sigma 3}$ are primary and secondary leakage inductances, $\mathrm{U}_{1}$ is secondary number of turns, $i_{1}, i_{2}, i_{3}$ are primary current, $2^{\text {nd }}$ and $3^{\text {rd }}$ secondary currents, $U_{\mathrm{D} 1}, U_{\mathrm{D} 2}$ are $1^{\text {st }}$ and $2^{\text {nd }}$ diodes' voltage, $\mathrm{H}(\mathrm{B})$ is the magnetizing curve of the core material, B is magnetic field $\mathrm{B}(\mathrm{T}), \varphi$ is magnetic flux, $\delta$ is air-gap length, $\mu 0$ is magnetic permeability of space, $1_{\mathrm{w}}$ is flux path length in the iron core. Time constant of the load in Eq. 5 is about several micro seconds.

\subsection{Bipolar Pulse Width Modulation (PWM) Switching}

The switching signal has come up with interacting of sinusoidal reference signal and the triangular wave. The sinusoidal reference signal determines the frequency of the inverter output voltage. Therefore, the frequency of the main harmonic component of the output signal becomes the frequency of the sinusoidal reference control signal. Frequency modulation and amplitude modulation directly affect the waveform of the output voltage. As the modulation frequency ratio and the amplitude modulation ratio increase, the eddy losses occurring in the transformer decrease [28]. 
Since the transformer is an inductive load, the harmonics that have occurred in the load current are weak due to the number of pulses at the output of the inverter. Inverter welding frequencies are between 400 and $2000 \mathrm{~Hz}$ frequencies typically. A frequency band from 1000 to $1200 \mathrm{~Hz}$ is used in the vast majority. It is thought that this frequency range is high enough to allow welding transformers to reduce their sizes by reducing magnetic core material. The same amount of conductor area must be maintained for a given output power. Raising the frequency higher leads to diminishing points in return. The size cannot be further reduced and parasitic losses from switching become greater [29].

\subsection{Medium frequency transformer design}

The medium frequency transformers which are at $1000 \mathrm{~Hz}$ to $5000 \mathrm{~Hz}$ are designed like conventional transformers. We have used a shell transformer core, since it produces less leakage inductance than the core one. The efficient length of the designed transformer's core is given in Figure 2.

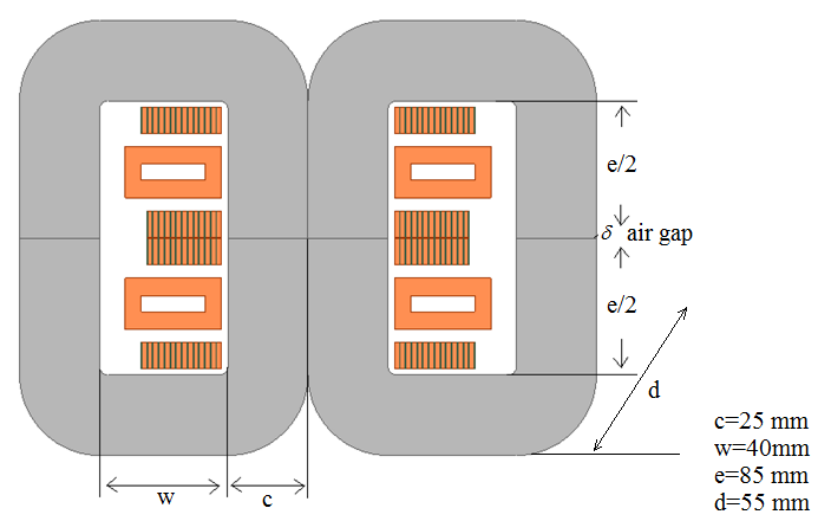

Figure 2. 2D view of the designed transformer

The core cross sectional area and primary winding number of turns are calculated by equations 6-7.

$$
\begin{aligned}
& A_{c}=\frac{U_{2} \cdot 10^{4}}{4 \cdot F \cdot f \cdot N_{2} \cdot B_{m}} \\
& N_{1}=\frac{U_{1} \cdot 10^{4}}{4 \cdot F \cdot f \cdot B_{m} \cdot A_{c}}
\end{aligned}
$$

where; U1, U2 are primary and secondary voltages $(\mathrm{V}), \mathrm{f}$ is frequency $(\mathrm{Hz}), \mathrm{F}$ is form factor, $\mathrm{Bm}$ is amplitude of AC flux component (T), Ac is core cross-sectional area $(\mathrm{cm} 2)$.

The total apparent power $(\mathrm{Pt})$, and the producer factor are given in equations 8-9. The cross-sectional area of conductor limits the window size.

$$
\begin{gathered}
P_{t}=P_{\text {out }}\left(\frac{1}{\eta}+1\right) \\
A_{p}=A_{c} W_{a}=2 . c . d \cdot W_{a}=\frac{P_{t} \cdot 10^{4}}{F \cdot B_{m} \cdot f \cdot K_{u} K_{j}}
\end{gathered}
$$

where; Pt is the total apparent power, $\eta$ is efficiency, $\mathrm{Wa}$ is core window area, $\mathrm{Ku}$ is frame filling factor, $\mathrm{Kj}$ is current density constant. The effective core length can be calculated by Eq. 10:

$$
l_{m}=2 w+2 e+\pi c
$$

where; $\mathrm{e}$ is frame height, $\mathrm{w}$ is frame width, $\mathrm{c}$ is width of leg (2.c is central leg of the shell type transformer). Sheet plates are packed as in insulated laminations, and they form the core of transformer. The core packaging factor affects the core dimensions. The lamination thickness is smaller than the skin depth. Therefore, it affects the eddy losses in the core.

$$
\delta=\sqrt{\frac{2}{\omega \mu \sigma}}
$$

where; $\delta$ is skin depth, $\omega$ is angular frequency, $\mu$ is relative magnetic permeability, $\sigma$ is conductivity. We have calculated the skin depths of the core and the copper as $0.385 \mathrm{~mm}, 2.1 \mathrm{~mm}$ respectively.

In shell type transformers, primary and secondary windings are made as cylindrical packages and settled between each other's in the same leg. In order to reduce effects of the leakage fluxes, the magnetic circuit turns around the windings in this structure. As the number of slices increases, the leakage flux decreases significantly [30]. In order to simplify production and to reduce the leakage currents for descending to an acceptable level, the winding structure was selected as three parts in primary and two parts in secondary. It is seen from the structure that the average length of the winding is long, but the average length of the magnetic circuit is short. Fig. 3 presents average lengths for different sizes in the winding. 
The Mean Length Turn, (MLT), is required to calculate the winding resistance and weight for any given winding [31].

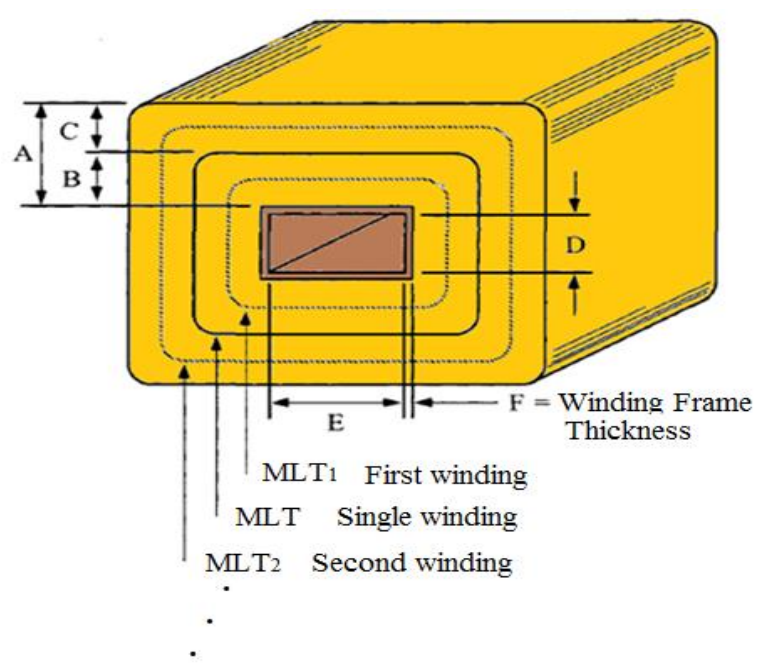

Figure 3. Different winding lengths [30]

The winding lengths of the transformers in Figure 3 can be calculated by Eq. 12-14. The primary and secondary currents and current density can be calculated by Eq. 15-17.

$$
\begin{gathered}
M L T=2(D+2 F)+2(E+2 F)+\pi A \\
M L T_{1}=2(D+2 F)+2(E+2 F)+\pi B \\
T_{2}=2(D+2 F)+2(E+2 F)+\pi(2 B+C) \\
I_{1,2}=\frac{P_{\text {in,out }}}{U_{1,2}} \\
I_{1,2 \% d_{g}}=I_{1,2 \% 100} \sqrt{\frac{100}{d_{g}}} \\
J_{1,2}=\frac{I_{1,2}}{A_{w 1, w 2}}
\end{gathered}
$$$$
M L T_{2}=2(D+2 F)+2(E+2 F)+\pi(2 B+C)
$$

where; $\mathrm{I}_{1}, \mathrm{I}_{2}$ are primary and secondary currents, $\mathrm{d}_{\mathrm{g}}$ is duty cycle, $\mathbf{J}_{1}, \mathbf{J}_{2}$ are primary and secondary current densities, $A_{w 1}, A_{w 2}$ are primary and secondary windings' conductor cross section. $\mathrm{K}_{\mathrm{U}}$ is an estimate of what $\%$ of the wire volume is actual copper.
The core window filling factor and resistance are given as in Eq. 18-20:

$$
\begin{gathered}
W_{a}>\frac{N_{1} A_{w 1}+N_{2} A_{w 2}}{K_{u}} \\
A_{p, s}=\frac{N_{1,2} A_{w 1, w 2}}{K_{u}} \\
R_{p, s}=\rho_{c u} \cdot N_{1,2} \cdot \frac{\left(M L T_{p_{1}, s_{1}}+M L T_{p_{2}, s_{2}}\right)}{A_{w 1, w 2}} \\
+\frac{M L T_{p_{3}, s_{3}}+\ldots+M L T_{p_{n}, s_{n}}}{A_{w 1, w 2}}
\end{gathered}
$$

where; $\mathrm{W}_{\mathrm{a}}$ is core window area, $\mathrm{A}_{\mathrm{p}}, \mathrm{A}_{\mathrm{s}}$ are primary and secondary winding cross sections, $R_{p}, R_{s}$ are primary and secondary resistances, $\rho$ is resistivity. Primary and secondary total resistances are given by Eq. 21. When effect of winding temperature to resistance change $\left(\gamma_{20}=0.0039\right)$ is taken care, the total primary and secondary resistances are found by Eq. 22:

$$
\begin{gathered}
\gamma=\left[1+\gamma_{20}(T-20)\right] \\
R_{p_{-} t o t, s_{-} t o t}=R_{p, s} \cdot \gamma
\end{gathered}
$$

where; $\gamma_{20}$ is temperature coefficient, $\mathrm{T}$ is material temperature as Celsius, Rp_tot,s_tot is change in winding resistances. Copper, core, hysteresis, eddy and additional eddy losses are calculated by Eq. 23-24:

$$
\begin{gathered}
P_{w}=R_{p_{-} t o t} I_{p}^{2}+R_{s_{-} t o t} I_{s}^{2} \\
P_{v}=P_{h}+P_{c}+P_{e} \\
P_{v}=k_{h} f B_{m}^{2}+k_{c}\left(f B_{m}\right)^{2}+k_{e}\left(f B_{m}\right)^{1,5}
\end{gathered}
$$

where; $P_{w}$ is copper losses, $P_{v}$ is total core losses, $P_{h}$ is hysteresis core losses, $\mathrm{P}_{\mathrm{e}}$ is eddy-current core losses, $\mathrm{P}_{\mathrm{e}}$ is excess core losses, $\mathrm{k}_{\mathrm{h}}$ is hysteresis core loss coefficient, $\mathrm{kc}$ is eddy-current core loss coefficient, $\mathrm{k}$ is excess core loss coefficient.

The voltage regulation and efficiency are calculated by Eq. 26-27:

$$
e(\%)=\frac{U_{20}-U_{2}}{U_{2}} \times 100
$$




$$
\eta=\frac{P_{i}-\left(P_{v}+P_{w}\right)}{P_{i}}
$$

where; $\mathrm{e}(\%)$ is voltage regulation, $\eta$ is frequency.

Medium frequency transformer windings are produced as in the form of pancake. The conductors of pancake windings are wound around a rectangular formed core with the widest face of the conductor oriented either horizontally or vertically [32]. It is thought that the winding arrangement is made as in the form of pancake, since that leakage flux is decreased significantly [30] in such pancake winding configuration. On the other hand, as the frequency increases, the reactance increases and the active resistance changes. As a result of this, winding losses increase too. This problem can be reduced by using multi-wire litz winding or foil winding $[33,34]$.

Taking $1 \mathrm{KHz}$ the leather effect and flow density into consideration, primary folio conductor size was taken as $1.5 \mathrm{~mm} \mathrm{X} 8 \mathrm{~mm}$, secondary winding block conductor size was taken as $30 \mathrm{~mm} \mathrm{X} 16 \mathrm{~mm}$ and cooling space was taken as $20 \mathrm{~mm} \mathrm{X} 5 \mathrm{~mm}$. Trafoperm N3 and 2605SA1 Amorphous material is used for the transformer core. The features of this material are given in Table 1:

Table 1. Properties of Trafoperm N3 and Amorphous 2605SA1 materials [35-36]

\begin{tabular}{|l|c|c|c|}
\hline & $\begin{array}{l}\text { Trafoperm } \\
\text { N3 Core }\end{array}$ & $\begin{array}{l}\text { Amorphous } \\
\text { 2605SA1 } \\
\text { Core }\end{array}$ & Units \\
\hline Alloy & $\% 3 \mathrm{SiFe}$ & $\begin{array}{c}\% 5-10 \\
\text { SiFeB }\end{array}$ & - \\
\hline $\begin{array}{l}\text { Saturation Flux } \\
\text { Density (B })\end{array}$ & 2.03 & 1.56 & $\mathrm{~T}$ \\
\hline $\begin{array}{l}\text { Curie } \\
\text { Temperature }\end{array}$ & 750 & 395 & ${ }^{\circ} \mathrm{C}$ \\
\hline $\begin{array}{l}\text { Thermal } \\
\text { Expansion }\end{array}$ & 12 & 7.6 & $\begin{array}{l}10^{-6} /{ }^{\circ} \mathrm{K} \\
- \\
10^{-6} /{ }^{\circ} \mathrm{C}\end{array}$ \\
\hline $\begin{array}{l}\text { Resistivity } \\
M L T_{2}=2(D+\end{array}$ & 0.4 & 1.3 & $\begin{array}{c}\mu \Omega \mathrm{m} \\
C)+2(E+2 F)+\pi(2 B+\end{array}$ \\
\hline Density & 7650 & 7180 & $\mathrm{~kg} / \mathrm{m}^{3}$ \\
\hline $\begin{array}{l}\text { Lamination } \\
\text { Thickness }\end{array}$ & 0.3 & 0.025 & $\mathrm{~mm}$ \\
\hline $\begin{array}{l}\text { Stacking } \\
\text { Factor }\end{array}$ & 0.96 & 0.89 & - \\
\hline
\end{tabular}

\section{Medium frequency transformer's analysis by finite element methods}

Analytical solution can provide an accurate and sufficient solution for designing electrical machines. However, both 2-Dimensional (2D FEM) and 3Dimensional (3D FEM) solution gives more accurate estimations [37] under the changed geometry, nonlinear conditions magnetic saturation, and efficient fringing at the winding's terminals. If electrical machines are designed by 3D finite elements method, important design parameters such as spinning flow, current density, winding inductance, and axial force can be determined with very high accuracy because real 3D structure of the machine is taken into account by 3D finite elements methods. When you use the method mentioned here, the cost and the time spent can be saved. The calculated parameters for the machine are given in Table 2.

Table 2. Parameters of medium frequency spot welding machine

\begin{tabular}{|l|l|l|l|l|l|}
\hline Parameter & Value & Unit & Parameter & Value & Unit \\
\hline$A_{c}$ & 22.6 & $\mathrm{~cm}^{2}$ & $R_{1}$ & 24.65 & $m \Omega$ \\
\hline$W_{a}$ & 34 & $\mathrm{~cm}^{2}$ & $R_{L}$ & 800 & $\mu \Omega$ \\
\hline$\delta$ & 10 & $\mu m$ & $R_{2,3}$ & 12.85 & $\mu \Omega$ \\
\hline$l_{m}$ & 35.6 & $\mathrm{~cm}$ & $L_{\sigma 2, \sigma 3}$ & 1 & $n H$ \\
\hline$N_{1}$ & 54 & - & $L_{L}$ & 1 & $\mu H$ \\
\hline$N_{2,3}$ & 1 & - & $M_{2605 S A l}$ & 5.8 & $\mathrm{Kg}$ \\
\hline
\end{tabular}

In terms of the parameters and in analytical data given in Table 2, a medium frequency transformer's external and dynamic analysis circuits are prepared for no-load working and loaded working conditions. Next, the analyzes are done by Ansys-Maxwell Circuit Editor. Under the determined working conditions, the regarding circuit is drawn within the circuit editor; afterward its circuit model is exported as .sph extension. The .sph extension file contains winding resistances of transformer and its working state. This is imported to the excitations part of the transformer model in Ansys Maxwell transient analysis. Figure 5 shows primary winding's current and change of transformer's core losses respectively under no-load working condition regarding to core materials.

Transformer core manufacturers define the loss factor regarding to the values of $\mathrm{C}, \mathrm{EI}, \mathrm{U}$, and core 
loss factor per kilogram. The amorphous transformer core (Metglas) determines core loss as given in Eq. 28 [35].

$$
P_{\text {coreloss }}=6.5 f^{1.51} B_{m}^{1.74}
$$

where; Pcoreloss is total core losses (W/kg), $f$ is frequency $(\mathrm{kHz}), \mathrm{Bm}$ is amplitude of $\mathrm{AC}$ flux component $(\mathrm{T})$.

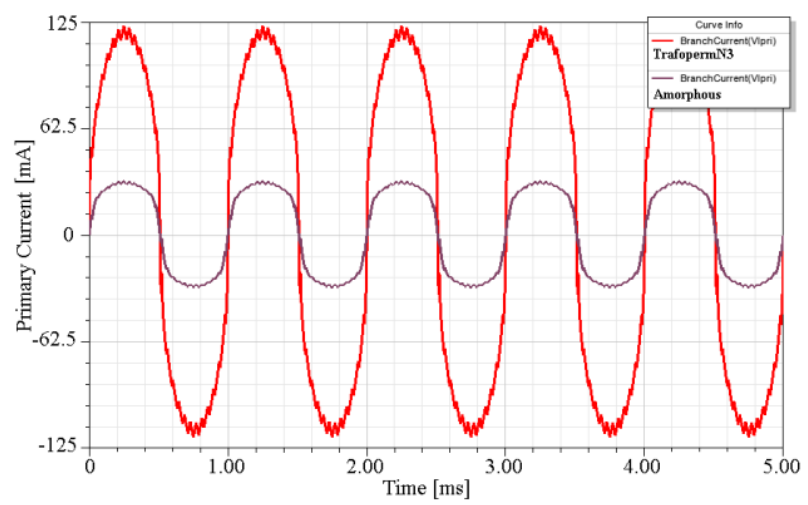

(a)

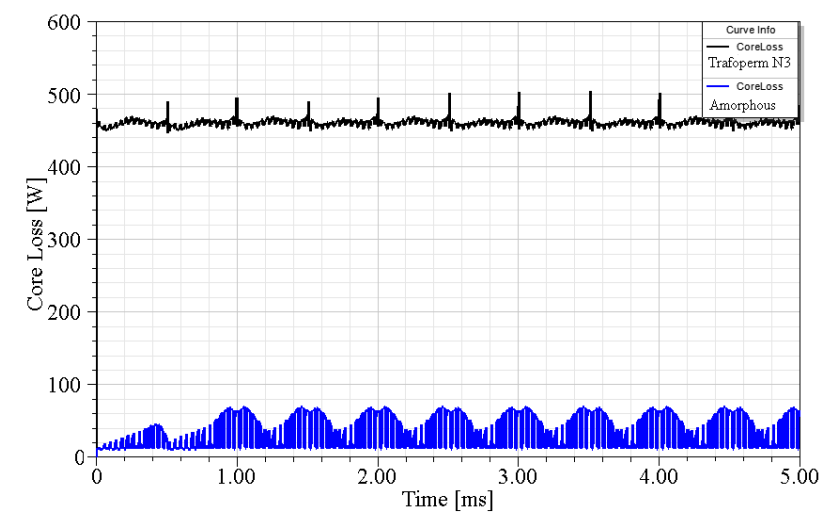

(b)

Figure 5. Change of primary winding's current (a) and change of transformer's core losses $(b)$

We have calculated total core losses as 37.7 Watts per $25 \square \mathrm{C}$ in regards to the manufacturer's definition (by Eq. 28). We have also found the average core losses for Amorphous structured core as $35.8 \mathrm{~W}$. On the other hand, when Trafoperm N3 material is used to make the core, core loss will be obtained as 460.3 Watts. From Fig. 6, it is expected that the magnetic field density at the inner corners of the core is high. Magnetic field values in these zones are below the core saturation point guaranteed by the manufacturer. The core losses have increased proportionally regarding to the flux density. Therefore, there will be losses at inner corners of monophase transformers and at the connection points of three phase transformers [38], hence the heatings shall become higher than the others.

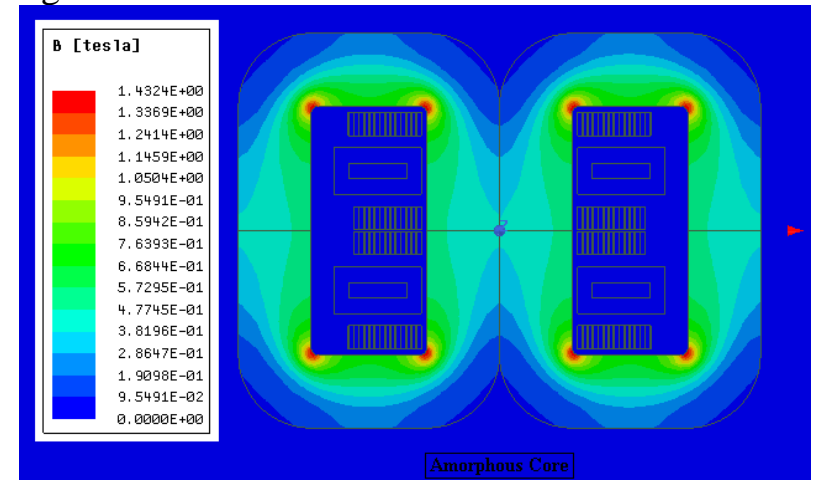

(a)

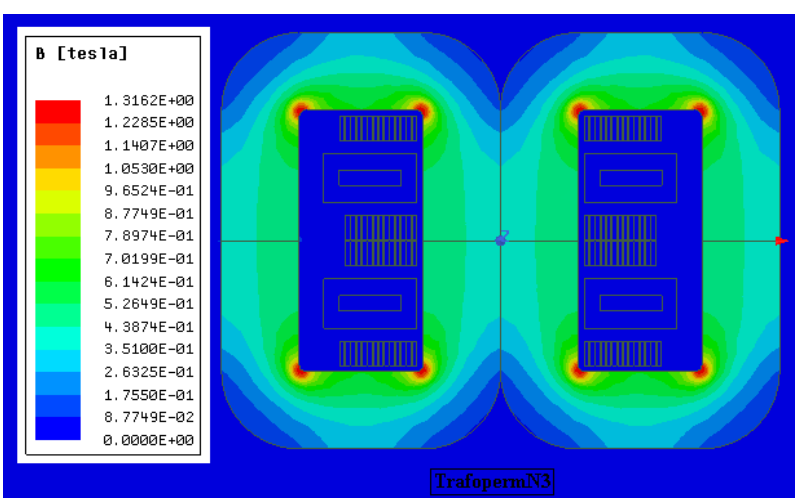

(b)

Figure 6. Change of magnetic flux and flux density Amorphous (a) and Trafoperm N3 (b), respectively

During the loaded working analysis of transformer, the arm resistance of spot-welding machine including welding electrode's and load's resistances are taken as $100 \mu \Omega, 800 \mu \Omega$ respectively. Afterwards, the analysis has continued by decreasing load resistances (as to be $600 \mu \Omega, 400 \mu \Omega$, and $100 \mu \Omega$ ).

The load value of the short-circuited secondary winding of the welding machine's transformer is too small. Hence, these windings are forced less than the short-circuited transformer's windings. That is why the windings are produced as forming with epoxy material. The forming by epoxy is convenient for reducing the heating effects to the windings.

As is known, type of load material at spot welding machines is related to the size of the lamination material. Due to this, secondary load currents change passing from several resistances and changes of load voltage are given in figures 7 and 8 . 


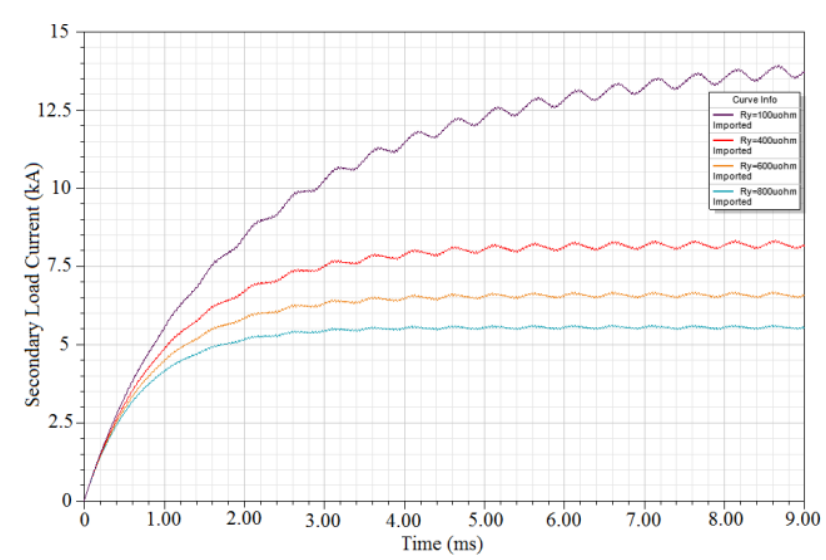

Figure 7. Change of secondary load current depending on load resistance

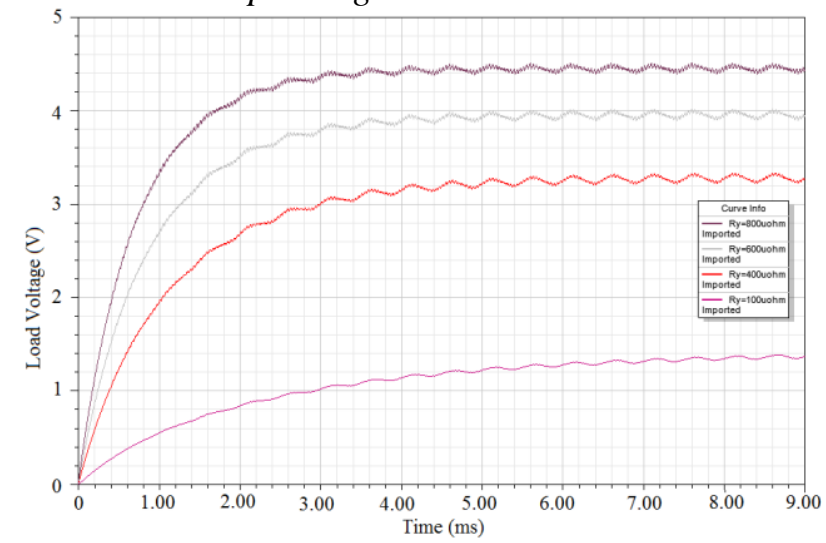

Figure 8. Change of secondary load voltage depending on load resistance

It is seen from figures 7-8 that as the load values decrease, the current passing through the load increases and voltages dropped on the load decrease. Therefore, it can be seen obviously that the time constant given in equation 5 shall change.

In the study, the designed transformer which has Amorphous material core was simulated, and analyzes were made under the loaded working conditions. The findings obtained from these simulations are similar to the findings obtained by using Trafoperm N3 material. However, it is seen that the secondary winding's current is about 200 A, which is higher than the other.

\section{Conclusions and discussions}

In the study, a medium frequency power transformer is designed and its transient parameters are calculated by using Maxwell 2D simulator. The analytical equations have figured out the transformer design thoroughly. The Trafoperm N3 core materials which have high Curie temperature and high performance were used in the analyses carried out. In case of using
Trafoperm N3 core materials instead of using Amorphous 2605SA1 core material, it is seen that the core losses have increased about 12.8 (460.3/35.8) times. The error rate between the core losses' value which was guaranteed by Amorphous core manufacturer and the core losses' value which was obtained from numerical calculations is $5 \%$.

The fact that sheet thickness of amorphous core is thinner when compared with Trafoperm N3 sheet results from a significant decrease of eddy losses.

It is thought that since Trafoperm N3 core has higher saturation flux density than amorphous core and since amorphous core works in a closer area to saturation in Figure 6, Trafoperm N3 is more suitable for $1 \mathrm{kHz}$. Compared to Trafoperm N3 core, due to Amorphous 2605SA1 core's low Cruie temperature, it is needed that the spot welding transformer performs the heat analyses. In addition, amorphous core is more expensive when compared with other siliceous steel.

Although it is known that Amorphous 2605SA1 material presents a good performance for more than $10 \mathrm{kHz}-20 \mathrm{kHz}$ frequency at power transformers nevertheless, we shall make trials to take the best magnetic outputs of Amorphous 2605SA1 material for 1 and $5 \mathrm{kHz}$ frequency values as well.

When compared with nanocrystal material, amorphous core has higher losses and it causes too much noise. However, the fact that nanocrystal material has lower Saturation Flux Density when compared with amorphous material increases size and core geometry costs.

It shall be possible to investigate effects of temperature and noise level in low frequencies, from this time onwards, numerically and experimentally. We consider finding out effects of Litz copper wires wrapped in the primary windings to a power transformer's size in future works. In addition, it is planned to conduct a $5 \mathrm{kHz}$ amorphous core transformer design in the future.

\section{References}

[1] Winkler, T., Doebbelin, R., Lindemann A., (2006) Mitigation of conducted emission of power electronic resistance welding equipment, 12th IEEE Power Electronics and Motion Control Conference, Portoroz, Slovenia, p.450455.

[2] Alfaro, S. C. A., et al. (2007). Comparison between $A C$ and $M F-D C$ resistance spot 
welding by using high speed filming. Journal of Achievements in Materials and Manufacturing Engineering, vol. 24-1, p.333-339.

[3] Wei, Li., et al. (2004). Energy consumption in $A C$ and MFDC resistance spot welding, XI the Sheet Metal Welding Conference, Heights, Michigan. p. 1-12.

[4] Batista M., Duarte Brandi S., (2013). Use of dynamic resistance and dynamic energy to compare two resistance spot welding equipments for automotive industry in zinc coated and uncoated sheets. American Journal of Engineering Research, vol.2-6, p.79-93.

[5] Nagasathya N., Boopathy S. R., Santhakumari A., (2013). MFDC-An energy efficient adaptive technology for welding of thin sheets, IEEE Energy Efficient Technologies for Sustainability Conference (ICEETS), Nagercoil, India, p. 901-906.

[6] Zellagui M., Hassan H. A., Abdelaziz A. Y. (2017). Non-Dominated Sorting Gravitational Search Algorithm For Multi-Objective Optimization of Power Transformer Design, Engineering Review, 37-1, 27-37.

[7] Wagmann L., Benčić Z., (2010). Stochastic Deterministic Method of Monte Carlo Simulation of Harmonic Currents at $\mathrm{Mv} / \mathrm{Lv}$ Transformer Stations. Engineering Review, 301, 23-34.

[8] Zidarič B., et al. (2005). Voltage feed welding transformer at no-load. Proceedings of the 5th WSEAS Int. Conf. on Power Systems and Electromagnetic Compatibility, Corfu, Greece, p.172-175.

[9] Stumberger G., et al. (2008). The impact of voltage generation on harmonic spectra of current and flux density in the welding transformer for a middle frequency resistance spot welding system. Industry Applications Society Annual Meeting, 2008. IAS'08, Canada, p. $1-8$

[10] Klopčič B., Stumberger G., and Dolinar D., (2007). Iron core saturation of a welding transformer in a medium frequency resistance spot welding system caused by the asymmetric output rectifier characteristics. In Industry Applications Conference, 2007. 42nd IAS Annual Meeting. Conference Record of the 2007, p.2319-2326.

[11] Podlogar V., et al. (2010). Magnetic core model of a midfrequency resistance spot welding transformer, IEEE Transactions on Magnetics, vol. 46-2, p.602-605.
[12] Popović, J., et al. (2011). Calculation of copper losses in resistance spot welding transformer with space-and time-dependent current density distribution, FEM and measurements. COMPEL - The international journal for computation and mathematics in electrical and electronic engineering,vol. 30-3, p.996-1010.

[13] Petrun, M., et al. (2012). Evaluation of iron core quality for resistance spot welding transformers using current controlled supply, IEEE Transactions on Magnetics, vol. 48-4, p.16331636.

[14] Gürdal, O., (2001) Designing of Electrical Machines, Atlas Publishing and Distribution, Ankara / Turkey, ISBN 975- 6574-07-0.

[15] Sakhno, L., et al. (2016). Field-Circuit Modelling of the Resistance Spot Welding Transformers, XXIV Symposium Electromagnetic Phenomena in Nonlinear Circuits, Helsinki, Finland, p.123-124.

[16] Černelič, J., et al. (2017). Eliminating short switching cycles when using hysteresis control of resistance spot welding systems. COMPELThe international journal for computation and mathematics in electrical and electronic engineering, vol.36-3, p.791-803.

[17] Suryakalavath, M., (2016). Control of Saturation level in the magnetic core of a welding transformer by Hysteresis Controller (HC) and Proportional Integral (PI) Controller. International Journal of Engineering Research and Applications, vol. 6-12, p.78-85.

[18] Rama, S., et al. (2017). Analysis of Proportional Integral and Optimized Proportional Integral Controllers for Resistance Spot Welding System (RSWS)-A Performance Perspective. IOP Conference Series: Materials Science and Engineering IOP Publishing. vol. 225-1.

[19] Dolinar, D., Klopčič, B., and Stumberger, G., (2010). Improvement of spot welding control system. Power Electronics and Motion Control Conference (EPE/PEMC), 2010 14th International, p. T4-28

[20] Petrun, M., et al. (2014). Determining the Parameters of a Resistance Spot Welding Transformer Using Differential Evolution, IEEE Transactions on Magnetics, vol. 50-4, p.1-4.

[21] Sakhno, L. I.,. et al. (2016). Аналитический Расчет Импеданса Трансформатора Машины Контактной Сварки, St. Petersburg Polytechnic University. Journal of Engineering 
Sciences and Technology, Saint Petersburg, p.57-64.

[22] Petrun, M., (2011). Iron Core Power Losses of an Medium Frequency Resistance Spot Welding Transformer, XIII International $\mathrm{PhD}$ Workshop, p.22-25.

[23] Petrun, M., et al. (2013). Hysteresis curves of a resistance spot welding transformer. COMPEL

- The international journal for computation and mathematics in electrical and electronic engineering, vol. 32-4, p.1404-1416.

[24] Engelmark, M., (2009). Usuability Evaluation of The Fiberous Core Sandwich Material Hybrix for Automobile Body, Master of Science Thesis, KTH Industrial Engineering and Management Machine Design, Stockholm, Sweden.

[25] Doğan, M.U., (2007). Investigation of Current and Voltage Splash and Penetration Effects in Conventional and Electronic Welding Machines, Master of Science Thesis.

[26] Wagner, M., \& Kolb, S. (2013). Efficiency improvements for high frequency resistance spot welding. 15th European Conference on Power Electronics and Applications (EPE), pp. 1-9.

[27] Jawad, S., et al. (2011). A study of IGBT rupture phenomenon in medium frequency resistance welding machine. Electrical Machines and Power Electronics and 2011 Electromotion Joint Conference (ACEMP), p. 236-239.

[28] Mohan, N., Tore M., Undeland., (2003). Power Electronics: Converters, Applications, and Design, 2nd Ed. John Wiley \& Sons, Inc.

[29] Bissell, H., Boilard, R, Selecting the Correct Size Inverter for DC Welding. Welding Technology Corporation, p.1-14
[30] Reinhard, Doebbelin., et al. (2009). Computerized calculation of leakage inductance values of transformers, Piers Online, vol. 85, p.721-726.

[31] Colonel W. T., McLyman., (2004). Transformer and inductor design handbook, Third Edition, Revised and Expanded California, U.S.A: Marcel Dekker, ISBN 0-8247-5393-3

[32] Xose M., López-Fernández., H. Bülent, Ertan., Janusz, Turowski., (2012). Transformers: Analysis, Design, and Measurement, CRC Press

[33] Charles R., Sullivan., (1999). Optimal choice for number of strands in a litz-wire transformer winding. IEEE Transactions on Power Electronics, vol.14-2, p.283-291.

[34] Arslan, S., Tarimer. I, Güven, M.E., (2013). Investigation of current density, magnetic flux density, and ohmic losses for single-veined, litz and foil structured conductors at different frequencies, Pamukkale University Journal of Engineering Sciences, vol.19-5, p. 195-200.

[35] http://www.webcitation.org/query?url=http $\% 3$ A\%2F\%2Ftrafo.ru\%2Fd\%2F803066\%2Fd\%2F 85266.pdf \&date $=2018-01-16$

[36] http://www.webcitation.org/query?url=http\%3 A\%2F\%2Fwww.vacuumschmelze.com\%2Find ex.php\%3Fid\%3D125\&date $=2017-07-12$

[37] Meier, S., et al. (2009). Design Considerations for Medium-Frequency Power Transformers in Offshore Wind Farms, 3th European Conference on Power Electronics and Applications, Barcelona.

[38] Karademir, A., and Eker, M.K., (2016). Effects Effect of the Different T-Joint Design at Power Transformer, Journal of Polytechnic, vol.19-4, p.389-397. 